\title{
Tyramine in Malt Beverages Interfering with Monoamine Oxidase Inhibitor Drugs
}

\author{
Naficeh Sadeghi'1,2,3, Mohammad Reza Oveisi1, Behrooz Jannat ${ }^{3}$, Masoomeh Behzad1, \\ Mannan Hajimahmoodi1, Esmaeel Zareakram1 \\ ${ }^{1}$ Department of Drug and Food Control, School of Pharmacy, Tehran University of Medical Sciences, Tehran, \\ Iran \\ ${ }^{2}$ Water Health Research, Ministry of Health and Medical Education, Tehran, Iran \\ ${ }^{3}$ Halal Research Center, Ministry of Health and Medical Education, Tehran, Iran \\ Email: ${ }^{*}$ janatbhr@sina.tums.ac.ir
}

Received 11 April 2016; accepted 5 August 2016; published 8 August 2016

Copyright (C) 2016 by authors and Scientific Research Publishing Inc.

This work is licensed under the Creative Commons Attribution International License (CC BY).

http://creativecommons.org/licenses/by/4.0/

(c) (7) Open Access

\section{Abstract}

The objective of this review is the determination of tyramine in 13 nonalcoholic beers (Maoshaieer) of Tehran market and survey of it's probably interaction with monoamine oxidase inhibitor drugs (MAOIs) has been investigated. Tyramine was at the highest levels in Baltika $(111.34 \pm 8.19 \mu \mathrm{g} / \mathrm{ml})$ and at the lowest level in Bitmalt $(8.01 \pm 2.09 \mu \mathrm{g} / \mathrm{ml})$. Comparing different flavors of malt drinks, the highest tyramine content was shown for classic or normal flavor (average $72.99 \pm 30.87 \mu \mathrm{g} / \mathrm{ml}$ ), while the lowest value belonged to cantaloupe flavored drinks (average $10.55 \pm 1.29 \mu \mathrm{g} / \mathrm{ml}$ ). In our study, it is seen that there is a significant difference between import and Iranian non-alcoholic beers, the import ones has more tyramine than Iranians. A number of 10 kinds of 13 samples interact whit MAOIs in one serving $(250 \mathrm{ml})$ usage $18.50 \mathrm{mg}$. The highest tyramine content of Iranian ones is $17.74 \mathrm{mg} / 250 \mathrm{ml}$ and for import ones is $27.83 \mathrm{mg} / 250 \mathrm{ml}$.

\section{Keywords}

Tyramine, Monoamine Oxidase Inhibitor Drugs, Maoshaieer, Nonalcoholic Beer

\section{Introduction}

Tyramines are decarboxylation products of tyrosine and phenylalanine, which are associated with headaches, migraine, hypertension and hyperthyroidism [1]. Tyramines are found in high amount in certain foods such as chocolates, wine, cheese, beans, banana peel, ketchup's and soya products [2]. Reports of hypertensive reactions

*Corresponding author.

How to cite this paper: Sadeghi, N., Oveisi, M.R., Jannat, B., Behzad, M., Hajimahmoodi, M. and Zareakram, E. (2016) Tyramine in Malt Beverages Interfering with Monoamine Oxidase Inhibitor Drugs. Journal of Biosciences and Medicines, 4, 1016. http://dx.doi.org/10.4236/jbm.2016.48002 
from monoamine oxidase inhibitors (MAOIs) began to proliferate in the early 1960s. Asatoor did extensive research and found that the combination of a MAOIs and a food containing tyramine resulted in the hypertensive interaction ("the cheese reaction"). Because of the risk of intracerebral hemorrhage and death, clinicians were hesitant to use the MAOIs. If tyramine in foods and drinks exceeds from $6 \mathrm{mg}$ in each serving it might interact with MAOIs Table 1 [3], although progress on the metabolic effects of MAOIs has been slow, use of clinical information in addition to analysis of bioactive amine content of foods has allowed the formulation of dietary recommendations, which are thought to be useful clinically in the administration of MAOIs. This has resulted in the gradual return to use of these psychotropic compounds [4]. Tyramine also serves as possible indicators of defective food manufacturing processes related with poor sanitary condition [5]. Decarboxylase action may accomplish by microorganisms involved in the manufacturing process (fermentation) for food such as wine, beer, etc. Biogenic amines can be formed almost as a consequence of described microbial activity and less by microorganisms responsible for decay of food. So at present it is a question, not a fact, that tyramine content of ceratin kinds of food could indicate the use of defective food manufacturing process. Hence tyramine determination has become important in food industries. Various analytical methods are available for quantification of tyramine such as spectrophotometric [6], gas chromatographic [7], reversed phase high performance liquid chromatography [8] and ion-exchange chromatography with pulsed amperometry [9]. These methods suffer from certain drawbacks such as time consuming, sample preparation, expensive equipments and trained person to operate Blackwell first described the interaction between MAOI drugs and tyramine in 1963 and named it the "cheese reaction”. As classic MAOI agents are still widely used in treating various psychological conditions including anxiety and depression, it seems essential to study their interaction with the tyramine present in foods and beverages. The aim of this study was the measurement of tyramine in nonalcoholic beers in Tehran retail markets, then the survey of any possible interaction between these nonalcoholic beers tyramine contents and MAOI drugs.

\section{Materials and Methods}

\subsection{Gathering Samples}

Eleven different brands of non alcoholic beers (Maoshaieer), including 5 imported and 8 national ones with various flavors, were selected. Flavor choice was based on its abundance in the market. Three samples out of each flavor of each brand were selected. Due to the lack of batch number on our national products; we had to use the manufacturing date in our study.

\subsection{Chemicals}

95\% acetic acid solution.

Mercuric sulfate-sulfuric acid solution (MS-SA reagent): $10 \mathrm{ml}$ concentrated sulfuric acid is added to $190 \mathrm{ml}$ distilled water and then $20 \mathrm{~g}$ mercuric sulfate is gradually added to the solution being continuously stirred in a constant-temperature bath.

$1.5 \%$ sodium nitrite solution: $750 \mathrm{mg}$ sodium nitrite is added to $50 \mathrm{ml}$ distilled water. The solution should be used fresh immediately after being prepared.

\subsection{Preparing Samples and Blank for Spectrophotometry}

Having poured $2 \mathrm{ml}$ of the sample into the test tube, we added $3 \mathrm{ml}$ of $95 \%$ acetic acid solution and $2 \mathrm{ml}$ of MS-SA reagent, shaking the tube well; the solution was then sonicated for 3 minutes. In blank tube we poured only $2 \mathrm{ml}$ distilled water, $3 \mathrm{ml}$ of acetic acid and $2 \mathrm{ml}$ of the reagent. Both tubes were placed in boiling water for 3 minutes and then allowed to reach the ambient lab temperature.

Table 1. Amounts of tyramine that interact with MAOI drugs.

\begin{tabular}{cc}
\hline The amount of tyramine $(\mathrm{mg})$ & Possible interference reaction \\
$6-8$ & Mild \\
$10-25$ & Moderate \\
$>25$ & Severe \\
\hline
\end{tabular}




\subsection{Colorimetry with Spectrophotometer}

Tyramine was determined spectrophotometrically at $500 \mathrm{~nm}$ (UV visible spectrophotometer, GBC Cintra 40, Victoria, Australia). The apparatus was initially calibrated using blank. The sample absorption was read at 500 $\mathrm{nm}$ wavelength (L1 value). In the next step, $0.2 \mathrm{ml}$ of fresh $1.5 \%$ sodium nitrite solution was added to both test sample and blank tubes, allowing them rest at ambient lab temperature for 15 minutes. Chromatic reaction was obvious after 15 minutes and the sample absorption was read again against the blank (L2 value). Pink to purple color appearing in the sample indicated the presence of tyramine.

L1: opacity, L2: opacity + color indication.

$\mathrm{L}=\mathrm{L} 2-\mathrm{L} 1$ : color indication in proportion to tyramine concentration.

\subsection{Method Validation}

To figure out the tyramine content of the samples based on the resulting absorption values ( $\mathrm{L}$ values), it was essential to draw standard curves. So the standard tyramine was used and a stock solution containing $200 \mathrm{mg} / \mathrm{ml} \mathrm{of} \mathrm{it}$ was prepared. Serially diluting the stock solution, then standard tyramine solutions prepared containing 10, 20, 30, $50,100,150$, and $200 \mu \mathrm{g} / \mathrm{ml}$. Absorption value of each of these concentrations was measured spectrophotometrically $(593 \mathrm{~nm})$ through adding the above-mentioned solutions and reagent and following the same procedure. The standard curved was drawn and the linear equation was obtained.

\subsection{Precision and Accuracy}

Three times daily for 3 consecutive days standard tyramine solutions with a concentration of $100 \mu \mathrm{g} / \mathrm{ml}$ were prepared and the measurements were repeated using these solutions to ensure the repeatability and the accuracy of the method. Also, sampling and measurement were repeated for one of the specimens 3 times daily for 3 consecutive days.

\section{Statistical Analysis}

Experimental data was analyzed using analysis of variance (ANOVA) and unpaired student's $t$-test using the SPSS software.

\section{Results and Discussion}

A number of 129 specimens of nonalcoholic beers were gathered prevailing in the Tehran market, including 18 imported and 105 national products. The highest tyramine value $(111.34 \pm 8.19 \mu \mathrm{g} / \mathrm{ml})$ was reported for Baltika (made in Russia), while the lowest value $(8.01 \pm 2.09 \mu \mathrm{g} / \mathrm{ml})$ belonged to Bit Malt. It should be noted that the highest tyramine value among the national brands belonged to Jojo $(70.98 \pm 25.01 \mu \mathrm{g} / \mathrm{ml})$. When comparing different flavors of malt drinks, the highest tyramine content was shown for classic or normal flavor (average $72.99 \pm 30.87 \mu \mathrm{g} / \mathrm{ml}$ ), while the lowest value belonged to cantaloupe flavored drinks (average $10.55 \pm 1.29$ $\mu \mathrm{g} / \mathrm{ml})$. Table 2 shows the tyramine content of imported and national samples imported brands compared to national products showed significant differences in tyramine content. The average values for national products and imported brands were $41.27 \pm 25.06 \mu \mathrm{g} / \mathrm{ml}$ and $60.91 \pm 38.10 \mu \mathrm{g} / \mathrm{ml}$, respectively, which it was more in imported brands significantly $(P<0.001)$. Statistical comparisons of different brands and different flavors revealed significant differences, the results of which are in detail presented in Figure 1. Table 3 shows the tyramine content of the different brands and the probability of unwanted interaction with MAOI drugs. Obviously

Table 2. Tyramine content of imported and national samples $(\mu \mathrm{g} / \mathrm{ml})$.

\begin{tabular}{ccccc}
\hline & Mean \pm SD & Number & Minimum & Maximum \\
Iranians & $41.27 \pm 25.06$ & 105 & 4.30 & 12.07 \\
Imports & $60.91 \pm 38.10$ & 24 & 4.04 & 120.14 \\
Total & $44.93 \pm 28.81$ & 129 & 4.30 \\
\hline
\end{tabular}

$P<0.001$. 


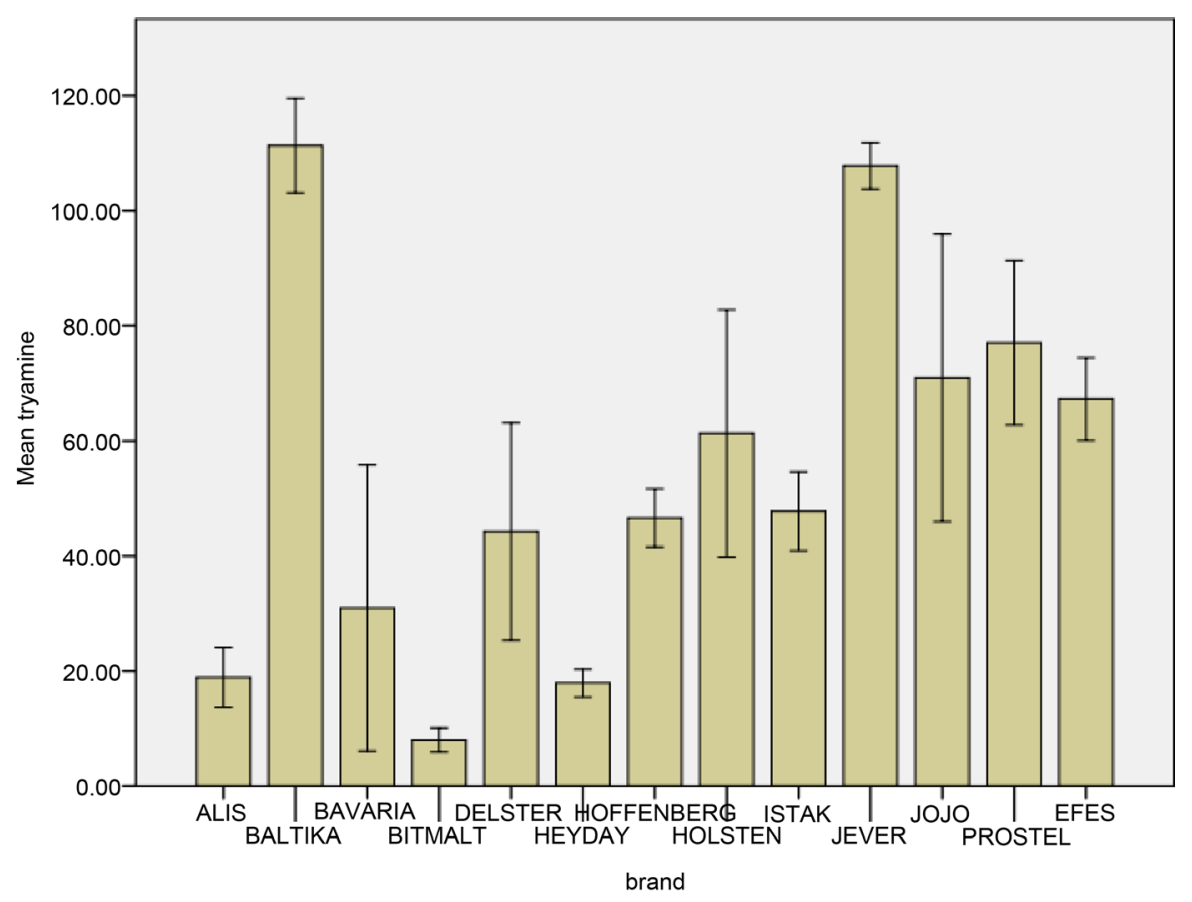

Figur 1. Comparison of the level of tyramine in several brands ( $\mu \mathrm{g} / \mathrm{ml})$.

Table 3. Tyramine content of the different brands and their probably interaction with MAOI drugs in 1 serving usage (250 ml).

\begin{tabular}{ccccccc}
\hline Brands & Mean \pm SD $(\mu \mathrm{g} / \mathrm{ml})$ & Number & Minimum & Maximum & Mean tyramine mg in $250 \mathrm{ml}$ & Interaction \\
\hline Bit Malt & $8.01 \pm 2.09$ & 15 & 4.30 & 11.64 & 1.97 & No interaction \\
Hey Day & $17.90 \pm 2.39$ & 6 & 14.82 & 20.94 & 4.47 & No interaction \\
Alis & $18.89 \pm 5.19$ & 12 & 11.85 & 24.89 & 4.72 & No interaction \\
Bavaria & $30.93 \pm 24.86$ & 12 & 12.07 & 73.02 & 7.70 & Mild \\
Delster & $44.23 \pm 18.89$ & 15 & 23.51 & 79.76 & 8.97 & Mild \\
Hoffenberg & $46.62 \pm 5.07$ & 15 & 36.59 & 52.50 & 12.65 & Moderate \\
Istak & $47.78 \pm 6.84$ & 15 & 42.74 & 62.61 & 11.99 & Moderate \\
Holsten & $61.29 \pm 21.48$ & 12 & 41.10 & 100.48 & 15.32 & Moderate \\
Efes & $67.27 \pm 7.18$ & 3 & 59.24 & 73.07 & 16.81 & Moderate \\
Jojo & $70.98 \pm 25.01$ & 15 & 47.38 & 126.04 & 17.74 & Moderate \\
Prostel & $77.07 \pm 14.03$ & 3 & 60.69 & 87.15 & 19.27 & Moderate \\
Jever & $107.79 \pm 3.98$ & 3 & 103.36 & 111.07 & 26.94 & Severe \\
Baltika & $111.34 \pm 8.19$ & 3 & 103.92 & 120.14 & 27.83 & Severe \\
Total & $44.93 \pm 28.81$ & 129 & 4.30 & 126.04 & & \\
\hline
\end{tabular}

all brands except three (Alis, Bit malt, Heyday) can even after one serving (250 cc) result in unwanted drug interactions when taking MAOIs. Two brands (Baltika and Jever) may also result in severe interactions after one serving. Table 4 shows the tyramine content of the different flavors. Table 5 shows tyramine concentration in malt with difference flavors non alcoholic beer. Studying the interaction between MAOIs and the tyramine contained in Iranian foods and beverages was considered by Tehran University Pharmacology Faculty Food Department and thus the tyramine content of widely used Iranian cheeses and yogurts was examined with the 
Table 4. Tyramine content of the different flavors $(\mu \mathrm{g} / \mathrm{ml})$.

\begin{tabular}{ccccc}
\hline Flavors & Mean \pm SD & Number & Minimum & Maximum \\
Cantaloupe & $10.55 \pm 1.29$ & 3 & 9.11 & 11.64 \\
Red grapes & $22.25 \pm 1.06$ & 3 & 21.10 & 23.13 \\
Pineapple & $26.33 \pm 18.99$ & 6 & 7.23 & 44.23 \\
Apple & $26.76 \pm 17.65$ & 15 & 7.15 & 53.93 \\
Tropical & $33.55 \pm 17.24$ & 12 & 6.39 & 51.09 \\
Strawberries & $34.10 \pm 3.95$ & 3 & 29.95 & 37.81 \\
Lemon & $36.90 \pm 20.58$ & 24 & 11.85 & 73.88 \\
Cherry & $37.92 \pm 2.86$ & 3 & 35.67 & 41.15 \\
Peach & $40.34 \pm 25.43$ & 15 & 4.30 & 93.19 \\
Pomegranate & $44.53 \pm 5.62$ & 9 & 36.59 & 53.74 \\
Malt & $72.99 \pm 30.87$ & 36 & 18.12 & 126.04 \\
Total & $44.93 \pm 28.81$ & 129 & 4.30 & 126.04 \\
\hline
\end{tabular}

Table 5. Tyramine content malt with difference flavors samples.

\begin{tabular}{ccccc}
\hline & Mean \pm SD & Number & Minimum & 126.04 \\
Malt & $72.99 \pm 30.87$ & 36 & 8.12 & 4.30 \\
Non Malt & $34.07 \pm 19.11$ & 93 & 93.19 & 4.30 \\
Total & $44.93 \pm 28.81$ & 129 & 126.04 \\
\hline
\end{tabular}

$P<0.001$.

conclusion that Iranian cheeses and yogurts could be classified as low tyramine products as a result of their production process and no interaction was therefore found with MAOIs. Evans declared the method suitable to measure the tyramine content and reported its recovery as $96 \%$ - 101\% when adding standard tyramine to samples. Besides measuring tyramine content by TLC and spectrophotometry, he also used HPLC with UV detectors and finally reported that the analyses by HPLC were less reliable than those by TLC and spectrophotometry. Tyramine recovery using HPLC was $82 \%-104 \%$. On the other hand, HPLC was not able to separate peaks of interfering agents contained in samples from those related to tyramine [10]. Tang et al. reported the amount of tyramine in Chinese beer samples that was found in the range of $2.96-7.15 \mathrm{mg} / \mathrm{Lit}$ [11]. The threshold level for intoxication of amines in samples is very difficult to establish, because it depends on individual responses and the presence of other amines [12]. Ten Brink et al reported that the amount $100-800 \mathrm{mg} / \mathrm{kg}$ of tyramine in foods was toxic [13], while Silla Santos suggested that the amount more than $1000 \mathrm{mg} / \mathrm{kg}$ (total amines in food) was hazardous for human health [14]. However, variations in the contents of biogenic amines in samples could be attributed to variability in the raw materials, collection period, and microbiological composition, as well as condition and duration of fermentation [15]. If the value of $6 \mathrm{mg}$ of tyramine reported by Ponto et al. to increase blood pressure is considered, $7.7 \%$ of s could provoke indirect toxicological effects in patients under treatment with MAOI drugs after consumption of $330 \mathrm{ml}$ of (volume of a normal sized can). If consumption of three cans (990 $\mathrm{ml}$ ) is considered the percentage is $23.1 \%$ [16]. Considering the studies dealing with the tyramine contents of yogurts, cheeses, and beers, we recommend such studies on other widely-used Iranian foods like meat products including fish (bloater) and sausages and fruits like strawberry and banana which are probable tyramine sources. Other studies can consider factors influencing the formation and accumulation of tyramine and other biogenic amines like PH, microbial contamination, and manufacturing and storage conditions, and focus on their impact on tyramine contents of various food products. Based on the results obtained through our study, it is highly recommended similar studies be planned in cooperation with the manufacturing companies and carried 
out during the production process. MAOI drugs are becoming safer for patients to use because of the interdisciplinary work of food scientists, pharmacologists, dietitians, physicians, nurses, and pharmacists. Each profession brings skills and knowledge to the science and its translation of food-drug interactions into patient's care. The compilation of table of tyramine malt drinks analyses can improve clinical decisions of practicing health care professionals. We also suggest the tyramine content and necessary cautions be printed on the product packages. After further careful studies, it may be necessary to inform the physicians prescribing and the patients taking MAOIs on the concurrent intake of malt drinks. The same dose of tyramine can cause a variety of effects in different individuals and clinically studying the hazardous dosage in Iranian population is therefore of tremendous importance. This review of tyramine illustrates variability of food components over time, progress of food industry toward a safer food supply, development of better drugs, and the necessity for medicine, nutrition, pharmacy, and food industry to work together. It is also recommended that a similar study be carried out to investigate the presence of other biogenic amines like histamine in the prevailing malt drinks.

\section{Acknowledgements}

Authors would like to thank the participants for their enthusiastic support. This work was student thesis and supported by grant (No.: 93-01-33-24030), from Tehran University of Medical Sciences.

\section{References}

[1] Lata, S., Yadav, S., Bhardwaj, R. and Pundir, C.S. (2011) Amperometric Determination of Tyramine in Sauce and Beer by Epoxy Resin Biocomposite Membrane Bound Tyramine Oxidase. Sensing and Instrumentation for Food Quality and Safety, 5, 104-110. http://dx.doi.org/10.1007/s11694-011-9117-5

[2] Halász, A., Baráth, A., Simon-Sarkadi, L. and Holzapfel, W. (1994) Biogenic Amines and Their Production by Microorganisms in Food. Trends in Food Science \& Technology, 5, 42-49. http://dx.doi.org/10.1016/0924-2244(94)90070-1

[3] http://www.mc.vanderbilt.edu.tyraminemenubook

[4] Brown, C., Taniguchi, G. and Yip, K. (1989) The Monoamine Oxidase Inhibitor Tyramine Interaction. The Journal of Clinical Pharmacology, 29, 529-532. http://dx.doi.org/10.1002/j.1552-4604.1989.tb03376.x

[5] Duong, H.D. and Rhee, J. (2007) Preparation and Characterization of Sensing Membranes for the Detection of Glucose, Lactate and Tyramine in Microtiter Plates. Talanta, 72, 1275-1282. http://dx.doi.org/10.1016/j.talanta.2007.01.028

[6] Silva, C.M.G. and Glória, M.B.A. (2002) Bioactive Amines in Chicken Breast and Thigh after Slaughter and during Storage at $4 \pm 1^{\circ} \mathrm{C}$ and in Chicken-Based Meat Products. Food Chemistry, 78, 241-248.

http://dx.doi.org/10.1016/S0308-8146(01)00404-6

[7] Staruszkiewicz, W.F. and Bond, J.F. (1981) Gas Chromatographic Determination of Cadaverine, Putrescine, and Histamine in Foods. Journal-Association of Official Analytical Chemists, 64, 584-591.

[8] Calbiani, F., Careri, N., Elviri, L., Mangia, A., Pistara, L. and Zagnoni, I. (2005) Rapid Assay for Analyzing Biogenic Amines in Cheese: Matrix Solid-Phase Dispersion Followed by Liquid Chromatography-Electrospray-Tandem Mass Spectrometry. Journal of Agricultural and Food Chemistry, 53, 3779-3783. http://dx.doi.org/10.1021/jf048037g

[9] John, C., Hoekstra, C. and Johnson, D.C. (1998) Comparison of Potential-Time Waveforms for the Detection of Biogenic Amines in Complex Mixtures Following Their Separation by Liquid Chromatography. Analytical Chemistry, 70, 83-88. http://dx.doi.org/10.1021/ac970806q

[10] Evans, C.S., Gray, S. and Kazim, N.O. (1988) Analysis of Commercially Available Cheeses for the Migraine Inducer Tyramine by TLC and Spectrophotometry. Analyst, 113, 1605-1606. http://dx.doi.org/10.1039/an9881301605

[11] Tang, T., Shi, T., Qian, K., Li, P., Li, J. and Cao, Y. (2009) Determination of Biogenic Amines in with Precolumn Derivatzation by High Performance Liquid Chromatography. Journal of Chromatography B, Analytical Technologies in the Biomedical and Life Sciences, 877, 507-512. http://dx.doi.org/10.1016/j.jchromb.2008.12.064

[12] Kalac, P., Savel, J., Krizek, M., Pelikánová, T. and Prokopová, M. (2002) Biogenic Amine Formation in Bottled Beer. Food Chemistry, 79, 431-434.

[13] Ten Brink, B., Damink, C., Joosten, H.M.L.J. and Huis in’t Veld, J.H.J. (1990) Occurrence and Formation of Biologically Active Amines in Foods. International Journal of Food Microbiolog, 11, 73-84. http://dx.doi.org/10.1016/0168-1605(90)90040-C

[14] Silla Santos, M.H. (1996) Biogenic Amines: Their Importance in Foods. International Journal of Food Microbiology, 29, 213-231. http://dx.doi.org/10.1016/0168-1605(95)00032-1

[15] Shukla, S., Park, H.K., Kim, J.K. and Kim, M. (2010) Determination of Biogenic Amines in Korean Traditional Fer- 
mented Soybean Paste (Doenjang). Food and Chemical Toxicolog, 48, 1191-1195. http://dx.doi.org/10.1016/j.fct.2010.01.034

[16] Ponto, L.B., Perry, P.J., Liskow, B.I. and Seaba, H.H. (1977) Drug Therapy Reviews: Tricyclic Antidepressant Monoamine-Oxidase Inhibitor Combination Therapy. American Journal of Health-System Pharmacy, 34, 954-961.

\section{Submit or recommend next manuscript to SCIRP and we will provide best service for you:}

Accepting pre-submission inquiries through Email, Facebook, LinkedIn, Twitter, etc. A wide selection of journals (inclusive of 9 subjects, more than 200 journals)

Providing 24-hour high-quality service

User-friendly online submission system

Fair and swift peer-review system

Efficient typesetting and proofreading procedure

Display of the result of downloads and visits, as well as the number of cited articles

Maximum dissemination of your research work

Submit your manuscript at: http://papersubmission.scirp.org/ 